Article

\title{
The Control of Venetian Blinds: A Solution for Reduction of Energy Consumption Preserving Visual Comfort
}

\author{
Francesco Nicoletti *(D), Cristina Carpino, Mario A. Cucumo and Natale Arcuri $\mathbb{D}$ \\ Mechanical, Energy and Management Engineering Department (DIMEG), University of Calabria, 87036 \\ Arcavacata di Rende (CS), Italy; cristina.carpino@unical.it (C.C.); mario.cucumo@unical.it (M.A.C.); \\ natale.arcuri@unical.it (N.A.) \\ * Correspondence: francesco.nicoletti@unical.it
}

Received: 6 March 2020; Accepted: 1 April 2020; Published: 5 April 2020

\begin{abstract}
Glazing surfaces strongly affect the building energy balance considering heat losses, solar gains and daylighting. Appropriate operation of the screens is required to control the transmitted solar radiation, preventing internal overheating while assuring visual comfort. Consequently, in the building design phase, solar control systems have become crucial devices to achieve high energy standards. An operation based on well-defined control strategies can help to reduce cooling energy consumption and ensure appropriate levels of natural lighting. The present study aims at investigating the effect of smart screening strategies on the energy consumption of a test building designed in the Mediterranean climate. With the aim of automatically setting the inclination of venetian blind slats, the necessary equations are analytically found out and applied. Equations obtained are based on the position of the sun with respect to the wall orientation. In the case of a cloudy day or an unlit surface, empirical laws are determined to optimize the shielding. These are extrapolated through energy simulations conducted with the EnergyPlus software. Finally, using the same software, the actual benefits obtained by the method used are assessed, in terms of energy and $\mathrm{CO}_{2}$ emissions saved in a test environment.
\end{abstract}

Keywords: smart solar shading; energy saving; venetian blinds

\section{Introduction}

Due to the extreme urgency of tackling climate change, it is necessary that buildings are as energy independent as possible [1]. It is important to implement measures for reducing energy consumption trying to take advantage of solar radiation [2,3]. European policies have identified energy efficiency in buildings as one of the key actions to limit greenhouse gas emissions [4]. The use of shielding devices is among the suggested interventions for energy conservation in buildings. An effective design of solar-control systems allows to reduce both cooling energy by preventing the transmission of direct-solar radiation in summer and heating energy maximizing solar gains in winter. Moreover, solar-control systems can help to reduce electricity for artificial lighting and ensure adequate visual comfort trying to take the most advantage of the healthy natural light. In addition to users' well-being, well-designed shielding devices can improve the architectural quality of the building. The type of shading used produces a different impact on the level of natural lighting, thermal comfort and visual comfort. Shielding systems can be divided into two categories, which are fixed and mobile systems [5]. The first category includes overhangs, external horizontal and vertical louvers, and egg-crates. The second category comprises venetian blinds, vertical blinds, and roller shades. In addition, according to the type of control, mobile systems can be furtherly distinguished in manual control, central up-down commands and fully automated control [6]. 
Several studies have investigated the effect of shading systems on thermal and daylighting performance of buildings. For example, the effect of external louver shading devices applied to different exposures of a building located at different latitudes was analyzed in [7]. Heating and cooling energy demand was quantified for different window and shading surfaces. A horizontal louver layout was considered for the South façade and a vertical louver layout was used for the East and West facades. Shading configuration (number of slats, tilt angle, spacing, distance from the window, and shading area) were optimized for each location in order to ensure adequate solar shading in summer and solar incidence in winter. The results showed that the implemented solar shadings are essential to reach internal comfort conditions and allow the achievement of significant energy savings for space cooling in all the studied locations. Horizontal shading, vertical shading and egg-crate shading were analyzed by [8] for a high-rise office building in Malaysia alongside different glazing configurations for the transparent facades. The authors demonstrated that cooling energy savings ranging from $5.0 \%$ to $9.9 \%$ can be obtained by applying the shields to all the facades with low-e double-glazing. Cooling energy saving will further increase between $5.6 \%$ and $10.4 \%$ if the shadings are applied to all facades with single clear glazing. [9] analyzed the effect of different fixed shading on the control of air temperature and the improvement of illuminance level of an office building in Jordan. Three types of shading (vertical fins, egg-crates and diagonal fins) were installed in three identical office and real-time experiments combined with computer simulations were adopted for thermal and daylight analyses proving that all shading devices help to improve thermal and visual environment in the office. [10] proposed an experimental configuration of an external shading device for apartment houses in south Korea. Simulations revealed that the experimental shading device, based on various adjustments of the slat angle, can offer the most efficient performance in terms of thermal and visual comfort for the occupants, compared to overhang, blind system, and light shelf, providing an energy saving of at least $11 \%$ during the cooling season. [11] carried out field measurements and simulations in order to assess the benefits of movable solar shadings on the energy, indoor thermal and visual comfort of a retrofitted residential building in Ningbo city in China. Results revealed that movable shading devices used for South facing windows can reduce building energy demand by about $34 \%$, improve thermal comfort in summer and visual comfort by $20 \%$ and drastically reduce risks of uncomfortable conditions by $80 \%$.

However, as observed by [12], manual or motorized blinds are limited in their ability to reduce energy consumption and to provide internal comfort because an operation of the blinds by the occupants themselves is expected to block direct solar radiation. On the contrary, the use of automated systems allows to more fully exploit the benefits of the blinds. The authors carried out thermal and visual experiments in a real scale test room and collected reports by the occupants of the dwelling in summer confirming the potential energy savings and the comfort enhancement when using automated blinds. [13] tested the applicability and effectiveness of an automated reflective shutter, which can work both as a sunshade and a daylight system. According to the results, the tested system was able to significantly improve daylight distribution and reduce energy consumption for artificial light by $60 \%$. [14] used simulation to investigate the potential savings in energy demand achievable through the installation of blind shadings and application of shading and lighting controls in an office building with fully-glazed façade in Qatar. Results have shown that by applying shading controls the space total energy demand is reduced by $11.6 \%$ in north-oriented facades and by $24.8 \%$ in east-oriented facades. If lighting controls are added, energy savings will increase to $14.1 \%$ in north-oriented offices and $28.3 \%$ in east-oriented offices.

Several authors have analyzed the interaction of the occupants with shields and artificial light trying to understand the influence of the automation level and the possibility of manual operation on the environmental and energy performance and the degree of user satisfaction. A field study of human interactions with motorized roller shades and dimmable electric lights in a high-performance office building is presented in [15]. Four different control set-ups were explored, namely (1) Manual control with low-level of accessibility (wall switches); (2) Manual control with high level of accessibility (web interface); (3) Fully automated control; (4) Automated control with manual overrides. Indoor 
environmental variables were monitored through sensors and a feedback by occupants on their indoor perception was obtained with a survey. The analysis revealed a preference for customized indoor climate with consequently different energy impacts. [16] reported two experiments investigating the effect of the level automation and the type of system expressiveness on users' satisfaction with an automated blinds system. They found out that the use of an expressive interface communicating the status and intentions of the blinds system could favor users' acceptance and satisfaction level, reducing the sense of losing control when decisions on environmental control are made by technology.

The analyzed literature highlighted the benefits in terms of energy saving and internal comfort achievable with the application of solar shades [17]. Moreover, the improvement of the shielding operation can also involve advantages from an economic point of view, since it reduces the waste of energy for air conditioning [18]. However, the activation and setting strategies of these systems require a more in-depth analysis in order to identify the most effective solutions that can lead to maximize their performance. The objective of the present work is to investigate the effect of a smart-control system applied to venetian blinds on the building energy use. In particular, an innovative control strategy is designed based on the identification of the optimal slat angle that is progressively adjusted following the sun position in order to take the best advantage of the available solar radiation. Therefore, the transmitted solar radiation is reduced when it generates an undesired thermal load while it is allowed to enter when there is a heating demand. The occupants' comfort is considered as well in the smart operation, seeking to guarantee a suitable minimum level of natural lighting and avoid direct exposure to solar radiation. The control strategy is based on the IoT technology because it requires the use of "cognitive" objects consisting of sensors and actuators, which are able to detect environmental data, process information, and implement the most appropriate actions needed to achieve the desired conditions. The information relating to the external and internal climatic conditions is acquired and used by the venetian blind actuators to orientate the slats. In a future development, technology can also be integrated with artificial intelligence networks in order to manage any preferences of the occupant. The training, in that case, can be conducted by interrogating the user so that he can communicate if he is not satisfied with the level of illumination of the environment.

It is a solution achievable thanks to home automation, useful for improving the quality of life and living comfort. The system is completed if it is integrated with other unplanned commands, such as turning the lights on or off according to the illuminance and the presence of the occupants.

\section{Venetian Blinds and Sensors}

Venetian blinds represent a common solution often adopted to allow the user to modify the incoming solar energy based on external weather conditions and his own sense of visual pleasure. They consist of small horizontal slats that can be manually oriented. The following characteristic parameters are defined for this type of shielding (Figure 1): distance between two consecutive slats $d$; slat depth $L$; slat inclination (angle between the normal to the surface of the slat and the horizontal plane) Slat.

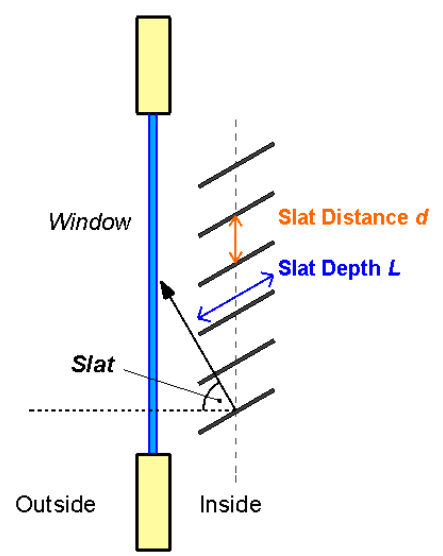

Figure 1. Schematization of venetian blinds. 
In order to automate the opening of the blinds, it is necessary to modify the inclination angle by means of an actuator implementing the desired shielding. Information from indoor and outdoor environment are needed to evaluate the optimal inclination in every moment of the day. In particular, an internal temperature sensor $\mathrm{T}$ and a presence detection sensor are required for each room.

In correspondence of each wall containing a glazed surface, a solarimeter is placed on the outside with the task of measuring the global irradiance $G$ incident on a vertical surface.

In addition to measuring the global irradiance value on the vertical surface, the solarimeter is used to understand if there is the presence of beam irradiance incident on the surface. The method to obtain this information consists in comparing the global irradiance measured by the solarimeter with the theoretical direct solar irradiance expected at that time of the day, estimated with the ASHRAE methodology [19]. Direct Normal irradiance is:

$$
I_{b n}=A e^{-\frac{B}{\sin \alpha}}
$$

in which $\alpha$ is the solar altitude, $A$ and $B$ are listed according to the month of the year [19]. The direct incident irradiance $G_{b}$ on a $90^{\circ}$ inclined surface is:

$$
G_{b}=I_{b n} \cos i
$$

where $i$ is the angle of incidence, obtained as a function of the solar altitude $\alpha$, the azimuth of the surface $\gamma_{w}$ and the solar azimuth $\gamma$ :

$$
\cos i=\cos \left(\gamma-\gamma_{w}\right) \cos \alpha
$$

If the global measured irradiance is lower than the theoretical direct irradiance, then there is certainly no incidence of sunlight on the surface; otherwise, with good approximation, we can assume that there is direct irradiance. This hypothesis is a precaution in the moments in which users must be protected from glare. This method, therefore, allows to discern between clear and cloudy days. Through various simulations conducted in the EnergyPlus environment, it has been possible to observe how this condition is useful for the purpose.

\section{Control Method}

The shields are managed to adapt to the various operating conditions outlined by the sensor outputs. The goal of the following analysis is to identify the Slat angle to be taken for each operating condition. First of all, it is necessary to distinguish two different operating conditions, relative to the presence or absence of occupants inside the environment.

\subsection{Absence of Occupants}

If the room is unoccupied, the lamellas position depends on the internal temperature detected, in order to understand if it is necessary to favor or block solar contributions.

\subsubsection{Winter Operation}

In the case of temperatures below the set-point value of $21^{\circ} \mathrm{C}$, the maximum solar radiation must be introduced into the environment, without worrying about the glare of occupants. The optimal inclination angle varies if the surface is exposed or not to direct solar radiation. In the negative case, the Slat value is $110^{\circ}$. Numerous tests conducted within the EnergyPlus simulation environment have shown that this angle guarantees the transmission of the maximum diffuse radiation. In the positive case, in which there is direct radiation incident on the glass surface, the slat of the venetian blinds is adjusted in order to be in a direction parallel to the sun's rays. The slats' inclination is, therefore, defined by the projection of the sun on the vertical plane perpendicular to the surface. Figure 2 shows the sun profile angle $\beta$ that the sun projection forms with the horizontal plane. 


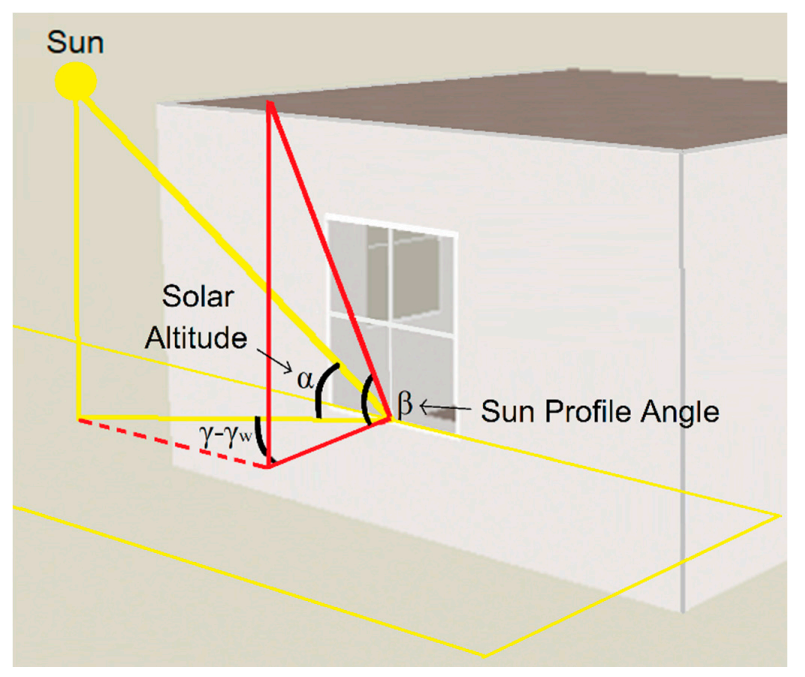

Figure 2. Relationship between sun profile angle, solar azimuth angle and solar altitude angle.

$\beta$ is obtained according to the following relation [20]:

$$
\beta=\arctan \left(\frac{\tan \alpha}{\cos \left(\gamma-\gamma_{w}\right)}\right)
$$

The method defined in this paper is structured according to the following logic. The results shown by the simulations allowed to validate these conditions. If $\beta$ is lower than $65^{\circ}$, the optimal slat angle is fixed equal to $\beta+90^{\circ}$, such as to keep the lamellas parallel to the solar rays.

Otherwise:

if $\mathrm{G}>300 \mathrm{~W} / \mathrm{m}^{2}$ direct component is high and the optimal slat angle is still $\beta+90^{\circ}$;

if $\mathrm{G}<300 \mathrm{~W} / \mathrm{m}^{2}$ direct radiation has a lower energy contribution than diffuse radiation, thus a Slat angle able to maximize the entry of the latter should be set. It is given by the following correlation:

$$
\text { Slat }=120^{\circ}-0.66 \alpha
$$

In the case of temperatures above the set-point value of $25^{\circ} \mathrm{C}$, shields must be completely shut since it is not necessary to guarantee natural illumination inside the environment.

\subsubsection{Intermediate Operation}

Finally, if the temperature is between $21-25^{\circ} \mathrm{C}$, Slat is fixed to $80^{\circ}$ (there is no need to exploit the solar contribution or even to shield).

\subsection{Presence of Occupants}

In the presence of occupants, three different cases are distinguished again.

\subsubsection{Winter Operation}

If the temperature is lower than the set-point value of $21^{\circ} \mathrm{C}$, solar radiation, which in this case is a free contribution, must be used as much as possible.

- $\quad$ The presence of direct radiation could cause visual discomfort on the work surface to people. In this case, the optimal configuration consists in shielding sun's rays by keeping the lamellas as open as possible. The requirement that guarantees this condition is that the vertex $\mathrm{A}$ of the lower lamella, the vertex $B$ of the upper lamella and the point representation of the sun are on the same line (Figure 3). The angle of inclination that identifies this position of the lamella is indicated in 
Figure 3 with the name of Slat*. In fact, if these points are aligned, certainly the sun's rays do not reach the work surface and the slats are the most open.

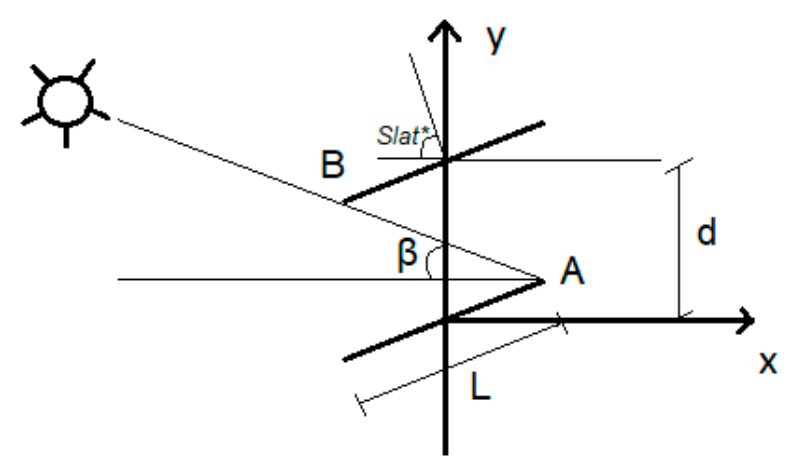

Figure 3. Limit inclination for direct radiation blocking.

with reference to Figure 3 , the coordinates of points $A$ and $B$ are the following:

$$
\left\{\begin{array} { l } 
{ x _ { A } = \frac { L } { 2 } \operatorname { s i n } ( \text { Slat } ^ { * } ) } \\
{ y _ { A } = \frac { L } { 2 } \operatorname { c o s } ( \text { Slat } ^ { * } ) }
\end{array} \quad \left\{\begin{array}{c}
x_{B}=-\frac{L}{2} \sin \left(\text { Slat }^{*}\right) \\
y_{B}=d-\frac{L}{2} \cos \left(\text { Slat }^{*}\right)
\end{array}\right.\right.
$$

Therefore, it is necessary that points $A$ and $B$ form the angle $\beta$ with respect to the horizontal:

$$
-\tan \beta=\frac{y_{B}-y_{A}}{x_{B}-x_{A}}=\frac{d-\frac{L}{2} \cos \left(\text { Slat }^{*}\right)-\frac{L}{2} \cos \left(\text { Slat }^{*}\right)}{-\frac{L}{2} \sin \left(\text { Slat }^{*}\right)-\frac{L}{2} \sin \left(\text { Slat }^{*}\right)}
$$

After some mathematical steps, Slat* results:

$$
\text { Slat }^{*}=2 \arctan \frac{\tan \beta+\sqrt{\tan ^{2} \beta-\left(\frac{d}{L}\right)^{2}+1}}{1+\frac{d}{L}}
$$

- If the direct solar radiation does not affect the walls, then the configuration that allows the maximum diffuse solar radiation to enter is Slat equal to $110^{\circ}$.

\subsubsection{Summer Operation}

For temperatures above the set-point value of $25^{\circ} \mathrm{C}$, it is necessary to shield the solar radiation, but not completely, so that a minimum of natural illumination is guaranteed. This is possible with Slat equal to $45^{\circ}$.

\subsubsection{Intermediate Operation}

If the temperature is between $21^{\circ} \mathrm{C}$ and $25^{\circ} \mathrm{C}$, the operation depends on the exposure to direct solar radiation: in the negative case, Slat is $80^{\circ}$; while in the case of exposure to direct solar radiation, the optimal angle is determined by equation (8) to avoid glare to the occupants.

\section{Definition of Simulation Environment}

The actual energy saving and operation of the smart-control strategy have been simulated in EnergyPlus. This software was selected for its renowned ability to accurately simulate and estimate the energy performance of buildings as well as its capability to properly integrate shading devices [14]. The building thermal zone calculation method in EnergyPlus is a heat balance model. The fundamental assumption of heat balance models is that air in each thermal zone can be modeled with uniform 
temperature. The fenestration module includes the ability to consider the angular dependence of transmission and absorption for both solar and visible radiation, and temperature-dependent U-value. In EnergyPlus, the calculation of diffuse solar radiation from the sky incident on an exterior surface takes into account the anisotropic radiance distribution of the sky. The sky model used for calculation is "CIE sunny clear day", with additional direct illumination from the sun. It has bright patches due to direct illumination from the sun with relatively dark areas where direct sunlight does not fall. The simulation tool allowed to evaluate the effectiveness of the system under dynamic conditions. Theoretical analysis and simulation are essential to test the operation of the devised smart system and to quantify its impact on energy consumption. The same approach has been adopted in other research works found in the literature [21-23], in which the effects of solar shading systems on energy demand and visual comfort were assessed by means of theoretical studies and simulations. However, this is intended to be a preliminary phase for the development of a prototype, which will be used to validate the conceived model with the aid of experimental data.

The problem was solved as a time-dependent model. The climatic parameters set refer to a year, obtained for the city of Cosenza (South Italy) from Meteonorm [24]. For the investigated location, the maximum value of external air temperature in summer is $36.4{ }^{\circ} \mathrm{C}$ and the minimum value in winter is $0.2{ }^{\circ} \mathrm{C}$. The maximum value of the direct normal solar radiation is $997 \mathrm{~W} / \mathrm{m}^{2}$ while the maximum value of the diffuse solar radiation on a horizontal surface is $489 \mathrm{~W} / \mathrm{m}^{2}$.

The test building consists of a $25 \mathrm{~m}^{2}$ square room designed to have a window for each exposure (Figure 4). The thermal transmittance values of external walls, floor and roof are equal to $0.38,0.34$, $0.27 \mathrm{~W} / \mathrm{m}^{2} \mathrm{~K}$, respectively. The stained glass windows represent the $15 \%$ of the total walls and are composed of double glass and air gap (4-12-4) with a thermal transmittance of $1.91 \mathrm{~W} / \mathrm{m}^{2} \mathrm{~K}$. The number of occupants is zero from $8.00 \mathrm{a}$.m. to $2.00 \mathrm{p} . \mathrm{m}$. and it is two during the rest of the day. The lighting system, equipped with linear control, is active from 7.00 a.m. to 8.00 a.m. and from 2.00 p.m. to 11:00 p.m. and ensure 500 Lux on the work surface, placed at $0.75 \mathrm{~m}$ above the ground. Finally, temperature control is managed by a fan coil system, always on, set at $20^{\circ} \mathrm{C}$ for winter days and $26{ }^{\circ} \mathrm{C}$ for summer days.

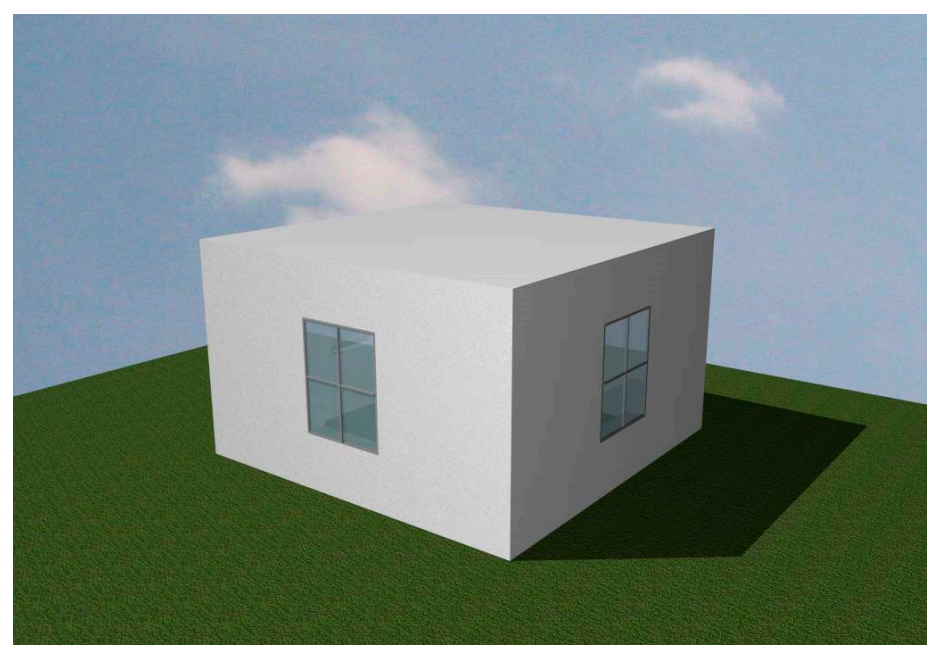

Figure 4. Test building.

\section{Analysis of Results}

In order to analyze the effects of smart shielding devices, the solar radiation transmitted with the dynamic control is compared with the solar radiation transmitted in the case of fixed shielding with an inclination angle of $80^{\circ}$.

Figure 5 shows the trends of three different contributes of irradiance $I$ for the different exposures: the global external radiation incident on the vertical surface $G v$, the solar radiation transmitted with the orientable shields Tadj and the solar radiation transmitted with the fixed shields Tfixed. In the figure, 
moreover, the lamellas inclination angle Slat, in case of activated control is reported. The simulations are conducted with reference to a typical day in the winter period (January 4th). In Figure 5a, relative to the East exposure, the gain deriving from the use of mobile shields emerges. In the early hours, they help to provide a greater solar contribution. The same considerations also apply to the Southern exposure (Figure $5 \mathrm{~d}$ ), in which Slat $=\beta+90^{\circ}$, with $\beta$ determined by the Equation (7). In the morning hours, for the North and West exposures, not directly illuminated by the sun, Slat is equal to $110^{\circ}$, such as to maximize the incoming diffuse solar radiation. From the graph displaying the west exposure (Figure 5c) emerges, instead, how dynamic control is implemented to ensure visual comfort in the presence of the occupants. The solar radiation transmitted, therefore, is limited from 15:00 to 17:00 by the control described by Equation (8).

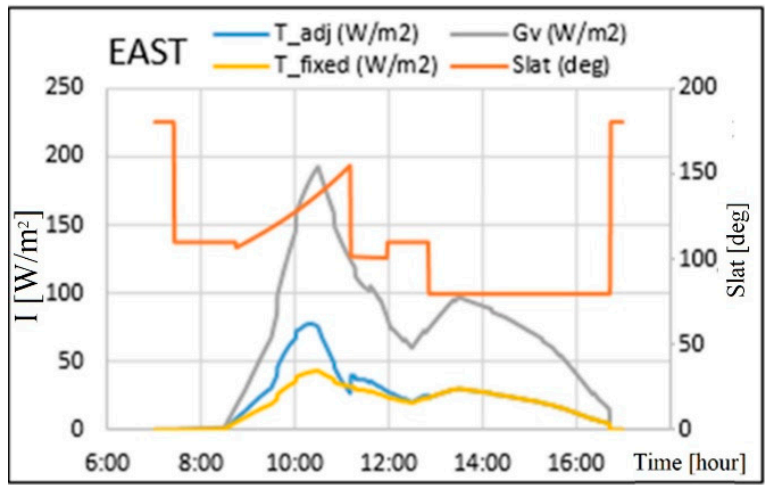

(a)

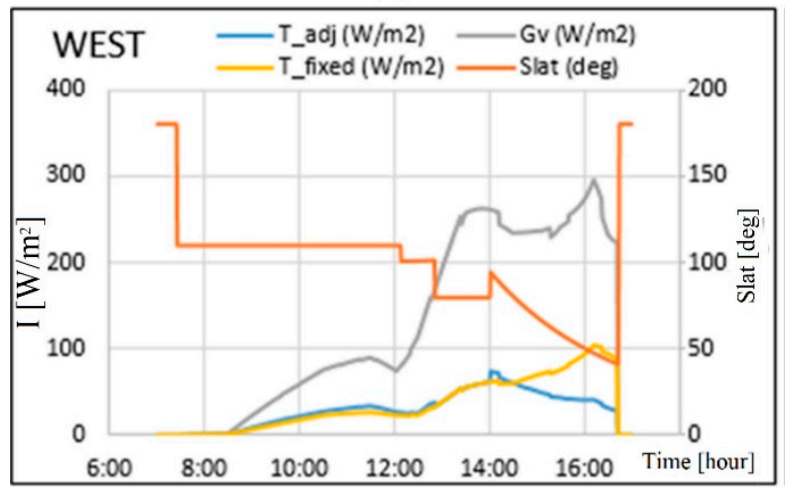

(c)

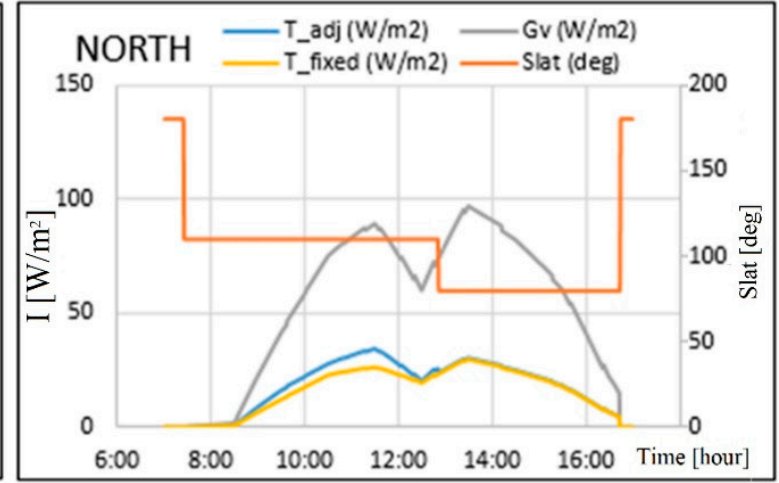

(b)

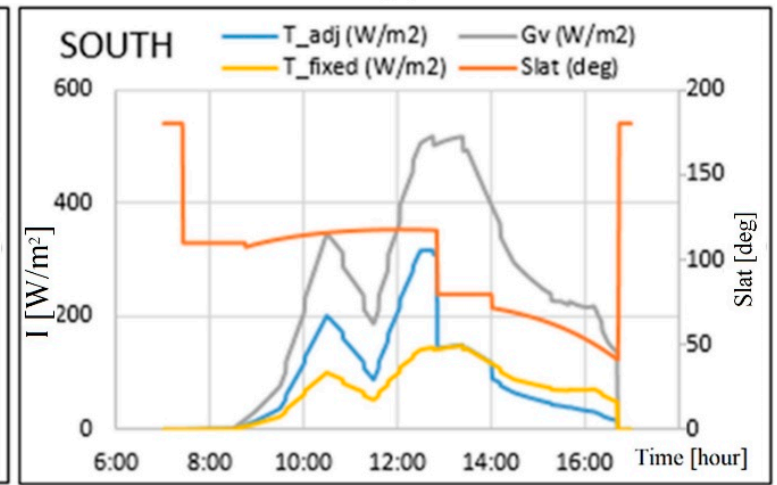

(d)

Figure 5. Irradiance and Slat angle in winter day for different exposure: (a) East (b) North (c) West (d) South.

For the south facade, which is exposed to solar radiation for long periods over the day, the double effect of the mobile shading systems emerges. In the first part of the day, they increase the incoming solar radiation while, in the second part of the day, they optimize the amount of solar radiation that can be transmitted in conjunction with the visual comfort of the occupants. Under the simulated conditions, the daily heating demand is $2.05 \mathrm{kWh}$ with the smart logic control and $5.38 \mathrm{kWh}$ with the fixed slat angle, obtaining a reduction of $62 \%$.

In Figure 6, instead, the same quantities are shown with reference to a typical day in the summer period (July 18th). 


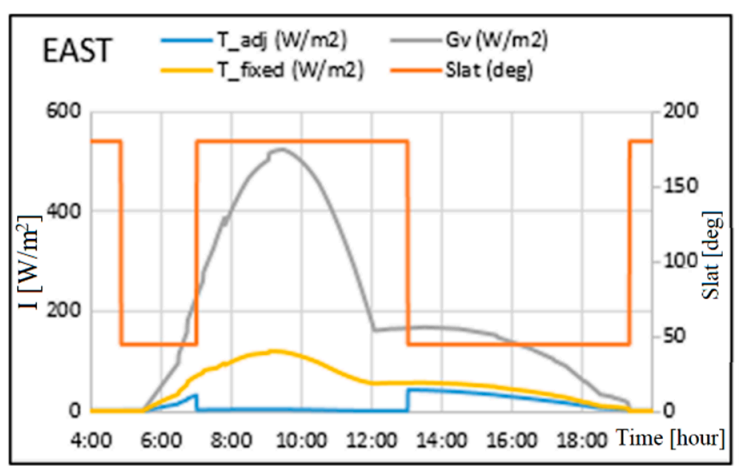

(a)

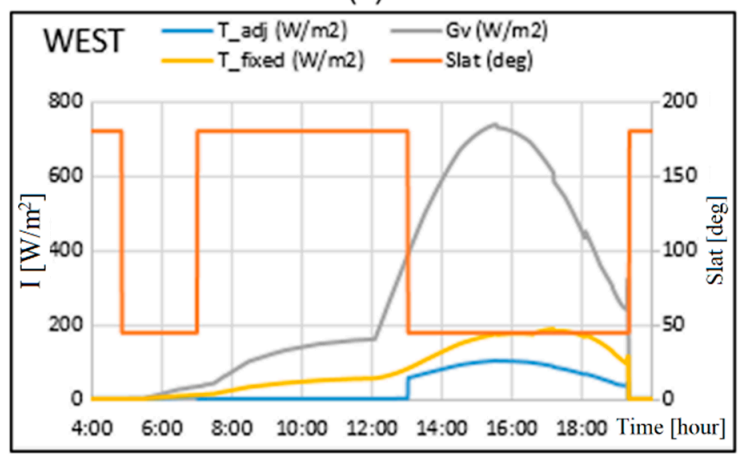

(c)

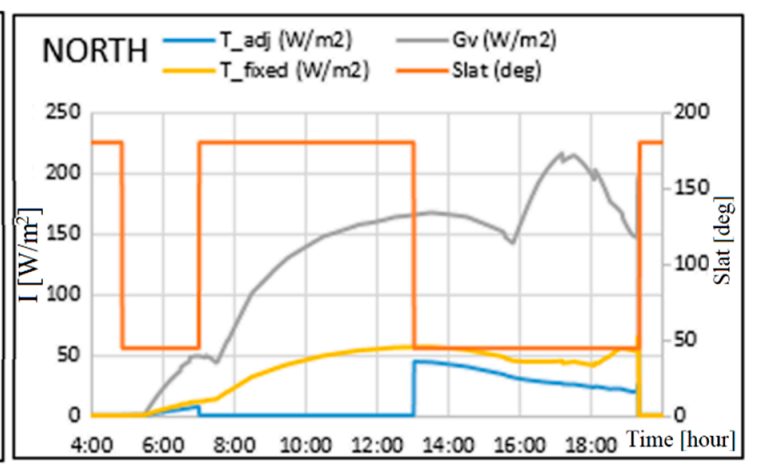

(b)

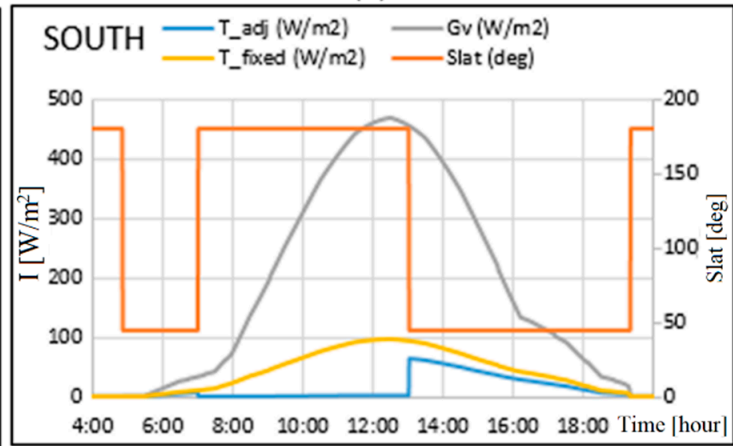

(d)

Figure 6. Irradiance and Slat angle in summer day for different exposure: (a) East (b) North (c) West (d) South.

In the conditions of a clear day and high outdoor temperature, the solar radiation transmitted through the windows must be shielded as much as possible and, therefore, the thermal load on the cooling system can be reduced. The graphs in Figure 6 show how the control, set up to keep the shields completely closed in the absence of occupants and at an angle of $45^{\circ}$ in the presence of occupants, guarantees its effectiveness by introducing into the environment a much smaller amount of solar radiation compared to the case with fixed shielding. The daily cooling energy demand is $11.5 \mathrm{kWh}$ with the smart logic control and $12.9 \mathrm{kWh}$ with the fixed slat angle, achieving a reduction of $10.8 \%$. Figure 7 shows the monthly requirements deriving from the sum of energy consumption related to heating, cooling and lighting. In every month there is a tangible reduction in consumption thanks to the application of intelligent control of shielding systems. The percentage saving is between $30 \%$ and $60 \%$ in the winter months and between $10 \%$ and $20 \%$ in the summer months. On an annual level, total saving is around $15 \%$.

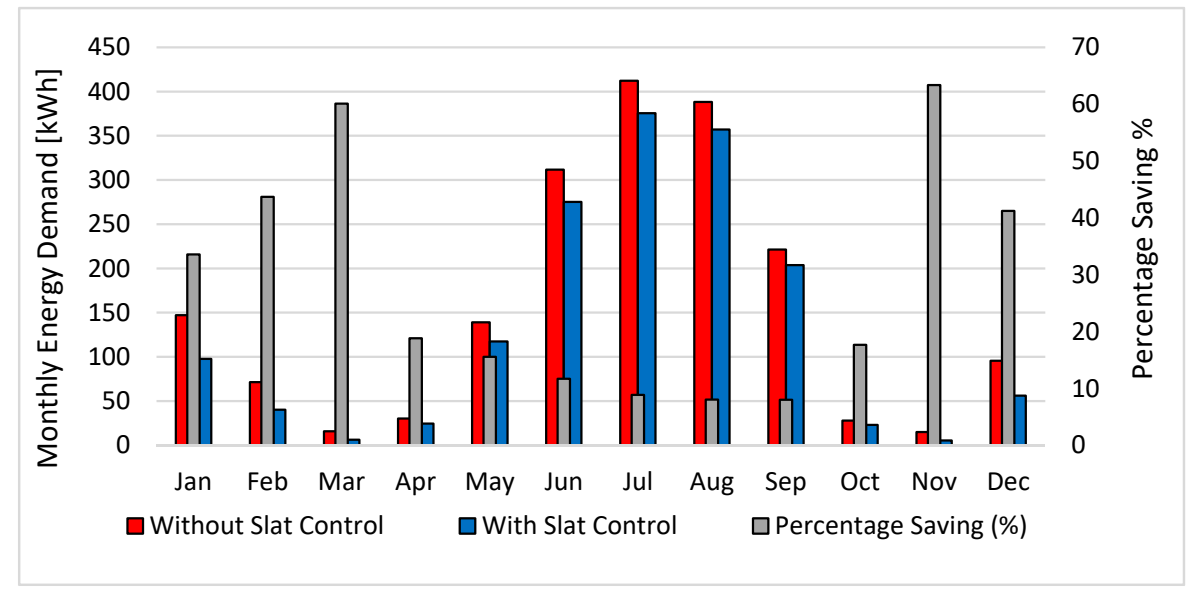

Figure 7. Monthly energy demand and percentage saving. 
Considering the energy demand satisfied by means of an electric heat pump with average efficiencies $\mathrm{COP}=3.5$ and EER $=3.0$, the values shown in Figure 8 are obtained for the annual supplied energy (electricity). The values are normalized with respect to the heated and cooled net area (19.36 $\mathrm{m}^{2}$ ). The figure also shows the energy costs calculated assuming an average electricity cost of 0.25 $€ / \mathrm{kWh}$ including Value-Added Tax [25]. The graph reveals that the application of the smart shading control allows to obtain savings in supplied electricity of about $5.0 \mathrm{kWh} / \mathrm{m}^{2}$.year, and an economic saving in the bill of $1.20 € / \mathrm{m}^{2}$.year.

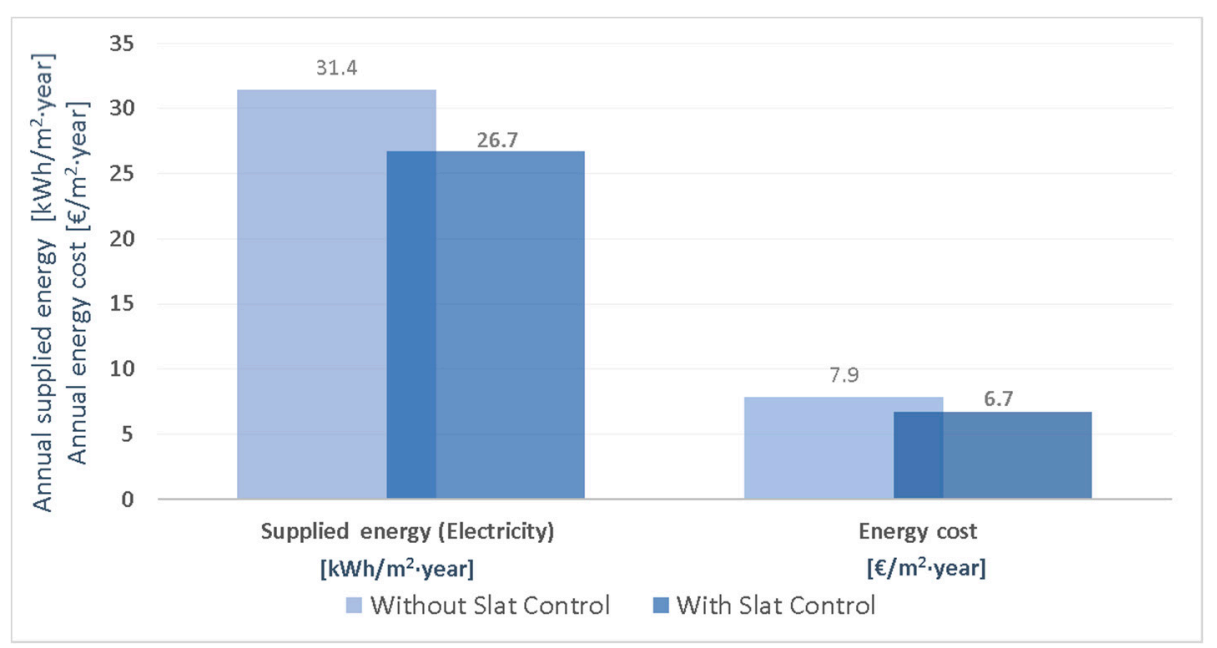

Figure 8. Savings of annual energy supply and correspondent reduction of the annual energy cost provided by the application of the smart shading control compared to the case without slats control.

By applying a nonrenewable primary energy factor of 1.95 [26] the annual source energy is calculated. Based on the results reported in Figure 9, the automated management strategy of the slats leads to a primary energy saving of $177.80 \mathrm{kWh} /$ year and a reduction of CO2 emissions of 79.2 $\mathrm{kgCO} 2 /$ year [27].

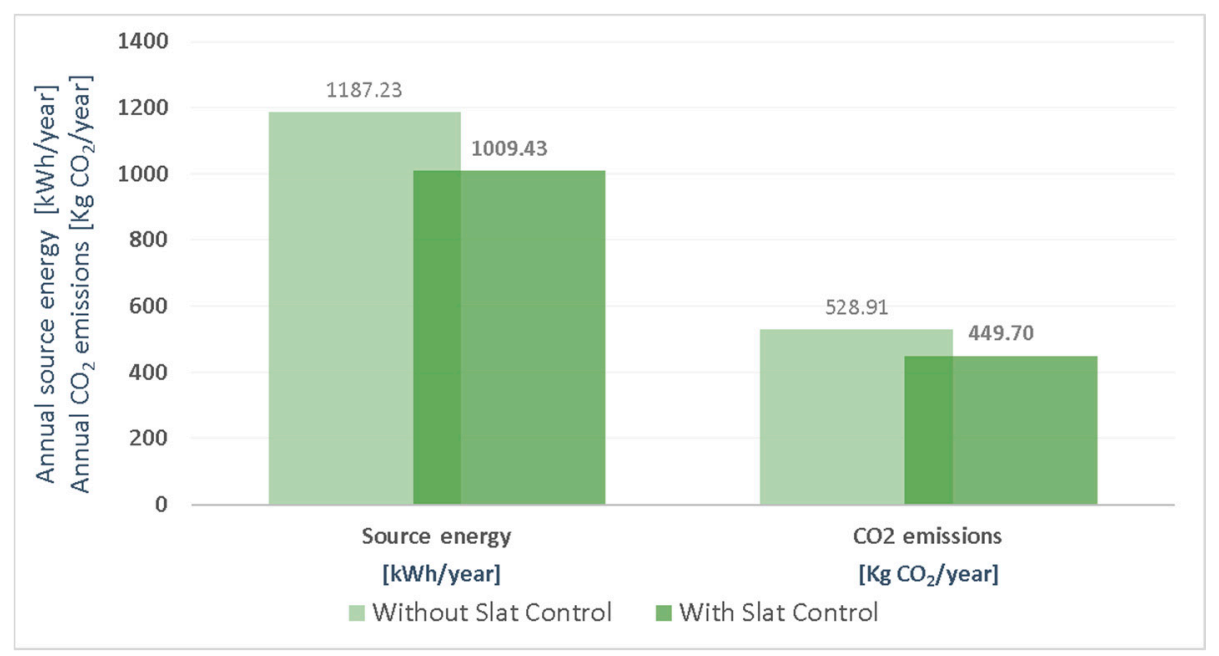

Figure 9. Saving of source energy and reduction of $\mathrm{CO}_{2}$ emissions obtainable through smart control of the venetian blinds.

It is worth noting that the evaluations are carried out on a simplified model of limited surface. By scaling up the problem to cases characterized by a larger building surface, the $\mathrm{CO} 2$ emissions reductions are even more significant, considering that savings of $4.10\left(\mathrm{~kg} \mathrm{CO} 2 / \mathrm{m}^{2} \cdot\right.$ year $)$ can be reached. 


\section{Conclusions}

The study focuses on the energy effects derived from the use of a system of internal mobile shields controlled with a precise control method, in order to determine any benefits on the energy needs of a residential building model for a specific location.

The use of mobile shields leads to a reduction in the energy demand for cooling during the summer period and guarantees an aid to the energy needs in the winter period, when solar radiation can help in reducing the energy waste for heating and lighting. Furthermore, the best shielding solution must protect the visual comfort of the occupants, who could be exposed to glare.

The dynamic control of the shields allows obtaining a considerable energy saving, with significant effects especially in the winter period. In one year, the estimated reduction in energy consumption for the analyzed building was $15 \%$.

The automation of venetian blinds can find wide diffusion and utility in domestic environments and offices. With reference to residential applications, clear advantages are constituted by energy saving and, therefore, by economic saving. Solar loads are managed automatically when the user is in another room in the house or away from home. This allows complete house management at all times. Another advantage is represented by the absence of visual discomfort caused by glare, an aspect that is also important in the workplace, in the office, to always maintain concentration.

Further developments and improvements on the control logic could concern the parametric study of the geometric characteristics of the slats, in order to identify the optimal configuration to be adopted during installation. It is also interesting to carry out the same study in other locations with different latitudes, in order to assess how much the location can influence the resulting benefits. A further development is represented by the implementation of the system in an experimental environment, in which it is supported by the machine learning logic to account for any human preferences.

Author Contributions: Conceptualization, F.N. and N.A.; methodology, F.N. and C.C.; software, F.N.; validation, C.C. and M.A.C.; formal analysis, N.A. and M.A.C.; investigation, F.N. and C.C.; resources, C.C.; data curation, F.N.; writing-original draft preparation, F.N. and C.C.; writing-review and editing, F.N. and C.C.; visualization, F.N. and C.C.; supervision, M.A.C. and N.A.; project administration, M.A.C. and N.A.; funding acquisition, F.N. and M.A.C. All authors have read and agreed to the published version of the manuscript.

Funding: This research was funded by Regione Calabria (PAC CALABRIA 2014-2020 - Asse Prioritario 12, Azione B) 10.5.12 - CUP H28D19000040006).

Conflicts of Interest: The authors declare no conflict of interest.

\section{References}

1. Bruno, R.; Bevilacqua, P.; Cuconati, T.; Arcuri, N. Energy evaluations of an innovative multi-storey wooden near Zero Energy Building designed for Mediterranean areas. Appl. Energy 2019, 238, 929-941. [CrossRef]

2. Bevilacqua, P.; Bruno, R.; Arcuri, N. Green roofs in a Mediterranean climate: Energy performances based on in-situ experimental data. Renew. Energy 2020. in-press. [CrossRef]

3. Bevilacqua, P.; Benevento, F.; Bruno, R.; Arcuri, N. Are Trombe walls suitable passive systems for the reduction of the yearly building energy requirements? Energy 2019, 185, 554-566. [CrossRef]

4. Directive 2010/31/EU of the European Parliament and of the Council of 19 May 2010 on the energy performance of buildings (recast). Off. J. Eur. Union 2010 2010, 3, 124-146.

5. Kirimtat, A.; Koyunbaba, B.K.; Chatzikonstantinou, I.; Sariyildiz, S. Review of simulation modeling for shading devices in buildings. Renew. Sustain. Energy Rev. 2016, 53, 23-49. [CrossRef]

6. Kuhn, T.E. State of the art of advanced solar control devices for buildings. Sol. Energy 2017, 154, 112-133. [CrossRef]

7. Palmero-Marrero, A.I.; Oliveira, A.C. Effect of louver shading devices on building energy requirements. Appl. Energy 2010, 87, 2040-2049. [CrossRef]

8. Lau, A.K.K.; Salleh, E.; Lim, C.H.; Sulaiman, M.Y. Potential of shading devices and glazing configurations on cooling energy savings for high-rise office buildings in hot-humid climates: The case of Malaysia. Int. J. Sustain. Built Environ. 2016, 5, 387-399. [CrossRef] 
9. Freewan, A.A.Y. Impact of external shading devices on thermal and daylighting performance of offices in hot climate regions. Sol. Energy 2014, 102, 14-30. [CrossRef]

10. Kim, G.; Lim, H.S.; Lim, T.S.; Schaefer, L.; Kim, J.T. Comparative advantage of an exterior shading device in thermal performance for residential buildings. Energy Build. 2012, 46, 105-111. [CrossRef]

11. Yao, J. An investigation into the impact of movable solar shades on energy, indoor thermal and visual comfort improvements. Build. Environ. 2014, 71, 24-32. [CrossRef]

12. Kim, J.H.; Park, Y.J.; Yeo, M.S.; Kim, K.W. An experimental study on the environmental performance of the automated blind in summer. Build. Environ. 2009, 44, 1517-1527. [CrossRef]

13. Hashemi, A. Daylighting and solar shading performances of an innovative automated reflective louvre system. Energy Build. 2014, 82, 607-620. [CrossRef]

14. Al Touma, A.; Ouahrani, D. Quantifying savings in spaces energy demands and CO2emissions by shading and lighting controls in the Arabian Gulf. J. Build. Eng. 2018, 18, 429-437. [CrossRef]

15. Sadeghi, S.A.; Karava, P.; Konstantzos, I.; Tzempelikos, A. Occupant interactions with shading and lighting systems using different control interfaces: A pilot field study. Build. Environ. 2016, 97, 177-195. [CrossRef]

16. Meerbeek, B.W.; de Bakker, C.; de Kort, Y.A.W.; van Loenen, E.J.; Bergman, T. Automated blinds with light feedback to increase occupant satisfaction and energy saving. Build. Environ. 2016, 103, 70-85. [CrossRef]

17. Bruno, R.; Pizzuti, G.; Arcuri, N. The Prediction of Thermal Loads in Building by Means of the en ISO 13790 Dynamic Model: A Comparison with TRNSYS. Energy Procedia 2016, 101, 192-199. [CrossRef]

18. Bruno, R.; Bevilacqua, P.; Arcuri, N. Assessing cooling energy demands with the EN ISO 52016-1 quasi-steady approach in the Mediterranean area. J. Build. Eng. 2019, 24. [CrossRef]

19. ASHRAE Handbook, Fundamentals; American Society of Heating, Refrigerating and Air-Conditioning Engineers: New York, NY, USA, 1989.

20. Hu, J.; Olbina, S. Illuminance-based slat angle selection model for automated control of split blinds. Build. Environ. 2011, 46, 786-796. [CrossRef]

21. Kim, D.W.; Park, C.S. Comparative control strategies of exterior and interior blind systems. Light. Res. Technol. 2012, 44, 291-308. [CrossRef]

22. Tzempelikos, A.; Athienitis, A.K. The impact of shading design and control on building cooling and lighting demand. Sol. Energy 2007, 81, 369-382. [CrossRef]

23. Yun, G.; Yoon, K.C.; Kim, K.S. The influence of shading control strategies on the visual comfort and energy demand of office buildings. Energy Build. 2014, 84, 70-85. [CrossRef]

24. Meteonorm. Meteonorm Global Meteorogical Database Version 7.1.8. 2017. Available online: https: //meteonorm.com/en/ (accessed on 26 March 2020).

25. Available online: https://www.arera.it/it/dati/eep35.htm (accessed on 26 March 2020).

26. Repubblica Italiana, D.M. 26 Giugno 2015-Parte 1. Applicazione Delle Metodologie di Calcolo Delle Prestazioni Energetiche e Definizione Delle Prescrizioni e dei Requisiti Minimi Degli Edifici; Gazzetta Ufficiale Serie Generale n.162 del 15-07-2015-Suppl. Ordinario n. 39; Istituto Poligrafico e Zecca dello Stato: Rome, Italy, 2015.

27. ISPRA-Istituto Superiore per la Protezione e la Ricerca Ambientale. Rapporti 303/2019; ISPRA: Rome, Italy, 2019; ISBN 978-88-448-0945-4.

(C) 2020 by the authors. Licensee MDPI, Basel, Switzerland. This article is an open access article distributed under the terms and conditions of the Creative Commons Attribution (CC BY) license (http://creativecommons.org/licenses/by/4.0/). 